\title{
Treating Lennox-Gastaut syndrome in epileptic pediatric patients with third-generation rufinamide
}

This article was published in the following Dove Press journal:

Neuropsychiatric Disease and Treatment

2I September 2010

Number of times this article has been viewed

Jessica Gresham'

Lea $S$ Eiland ${ }^{2,3}$

Allison M Chung 2,4

'Auburn University, Harrison School of Pharmacy (AUHSOP), ${ }^{2}$ Department of Pharmacy Practice, AUHSOP, ${ }^{3}$ University of Alabama, School of Medicine, Huntsville Regional Medical Campus, ${ }^{4}$ University of South Alabama School of Medicine, Department of Pediatrics, Mobile, Alabama, USA
Correspondence: Allison M Chung Auburn University, Harrison School of Pharmacy, Technology and Research Park, Bldg 3, Suite 2100, 307 University Blvd N, Mobile, AL 36688, USA

Tel + I 25I 4459300

Fax + | 25| 445934 |

Email chungam@auburn.edu
Abstract: Lennox-Gastaut syndrome (LGS) is a rare but debilitating pediatric epileptic encephalopathy characterized by multiple intractable seizure types. Treatment of LGS is challenging because of the small number of antiepileptic drugs (AEDs) which are effective for this syndrome, as well as the need for polytherapy in the majority of patients. This review focuses on the treatment of LGS with rufinamide, a recently approved third-generation AED with reported efficacy as adjunctive therapy for LGS. All relevant papers identified through a PubMed search on the treatment of LGS with rufinamide were reviewed. To date, the literature suggests improvements in seizure frequency for pediatric patients with LGS on rufinamide. Rufinamide appears to be especially effective for atonic or drop attack seizures. Rufinamide also displays a favorable adverse event profile compared with the older anticonvulsants, as well as a minimal number of drug interactions, making it a promising option for the adjunctive treatment of seizures associated with LGS.

Keywords: epilepsy, Lennox-Gastaut syndrome, pediatrics, seizure, rufinamide

\section{Introduction}

Lennox-Gastaut syndrome (LGS) is an uncommon but refractory epileptic encephalopathy of childhood, with a peak onset at 3-5 years of age. ${ }^{1-3}$ It is classified by the International League Against Epilepsy as a symptomatic generalized syndrome and requires a triad of clinical characteristics for diagnosis. ${ }^{4}$ First, patients exhibit an interictal slow spike-and wave pattern (less than $2.5 \mathrm{~Hz}$ ) on the electroencephalogram with paroxysmal fast rhythms $(10 \mathrm{~Hz})$ during sleep. The second characteristic is multiple generalized seizure types. Tonic seizures (often during sleep), atonic or drop attack seizures, and atypical absence seizures are the most common types; however, patients may also exhibit myoclonic generalized tonic-clonic, partial absence, and unclassified seizures. The third characteristic is cognitive impairment, with severe mental retardation found in more than half of patients. ${ }^{1,4-6}$

LGS accounts for only $1 \%-4 \%$ of all childhood epilepsies, but is viewed as one of the most difficult epilepsies to control. ${ }^{4}$ In many cases the etiology is unknown, and the presentation of multiple seizure types often leads to antiepileptic drug (AED) polytherapy. ${ }^{7}$ The multidrug and high-dose regimens required increase the risk for drug interactions, thereby affecting adjunctive AED serum concentrations and increasing the risk of medication overdose or ineffective treatment. Moreover, most of the AEDs have intolerable adverse effects or can exacerbate different seizures which occur within LGS. Only a few AEDs have been shown to be effective for LGS. ${ }^{8}$ Even with AED polytherapy, the long-term prognosis is poor, with a persistence of epilepsy in more than 
$75 \%$ of patients. ${ }^{9}$ This incomplete seizure control often results in significant lifetime health care costs for the patient. ${ }^{10}$

A patient's quality of life is very poor, with drop attacks being the most troubling presentation of LGS. These are the most physically damaging seizures, often causing head injuries due to falls. ${ }^{11}$ Therefore, many patients require close supervision, protective headgear, or confinement. A reduction in drop attacks is one of the most clinically significant outcomes for patients with LGS. ${ }^{12}$

The treatment goals for LGS are to provide the best seizure control possible using the fewest medications, while limiting the risk of adverse events. ${ }^{13,14}$ Currently, valproic acid is considered first-line therapy, and is considered effective for multiple seizure types in LGS; however, its use is not supported by controlled trials. Furthermore, the risk of life-threatening hepatotoxicity appears to be greater in children under two years of age, and valproate consequently tends to be avoided in this subgroup if other options are available. ${ }^{15}$ Topiramate, lamotrigine, and felbamate have demonstrated efficacy as adjunctive therapies in randomized, placebo-controlled trials. ${ }^{16-18}$ Topiramate and lamotrigine are currently recommended as second-line therapy and have comparatively more favorable tolerability. ${ }^{15,19}$ Felbamate lacks sedative effects, but it also carries serious risks of aplastic anemia and hepatotoxicity which limit its use. ${ }^{19}$ Clobazam, a benzodiazepine with less sedative potential than other members of its class, is also a potential adjunctive treatment. ${ }^{20}$ Other treatment options include zonisamide, a ketogenic diet, vagus nerve stimulation, or corpus callostomy. ${ }^{15,19}$

Due to the limited success of treatments for LGS, there is still a great demand for novel medications to manage this syndrome. An ideal medication would be effective in reducing the multiple seizure types associated with LGS, have a tolerable side effect profile, and have limited drug-drug interactions with other AEDs.

The antiepileptic efficacy and tolerability of rufinamide was established in a clinical trial which led the United States Food and Drug Administration (FDA) to grant it orphan drug status in 2004. Rufinamide then received FDA approval in early 2009 for adjunctive treatment of seizures associated with LGS in patients four years and older, as well as for adjunctive treatment of partial seizures in adults and adolescents. The purpose of this review is to analyze the current literature describing rufinamide use for the treatment of LGS.

\section{Methods}

A PubMed search was conducted by the authors for available studies limited to the terms "rufinamide" and "Lennox-Gastaut syndrome". Study population were evaluated for pediatrics and review article references were compared to search results.

\section{Rufinamide}

Rufinamide [1-(2,6-difluoro-phenyl)methyl-1H-1,2, 3-triazole-4-carboxamide], Banzel ${ }^{\circledR}$ (Eisai Co., Woodcliff Lake, NJ) is a third-generation AED with a triazole structure that has some similarity to lamotrigine. ${ }^{21}$ It mainly acts by prolonging the inactive state of sodium channels, inhibiting the firing of sodium-dependent action potentials. ${ }^{22}$

\section{Pharmacokinetics/pharmacodynamics}

Rufinamide is a lipophilic compound manufactured as $200 \mathrm{mg}$ and $400 \mathrm{mg}$ coated tablets. ${ }^{23} \mathrm{~A}$ suspension is not currently available; however, a study of extemporaneously compounded suspensions of rufinamide $(40 \mathrm{mg} / \mathrm{mL})$ in a 1:1 mixture of Ora-Plus ${ }^{\circledR}$ and Ora-Sweet ${ }^{\circledR}$ or Ora-Sweet $\mathrm{SF}^{\circledR}$ were found to be stable for at least 90 days. ${ }^{24}$

Rufinamide is not soluble in water and dissolves poorly in gastric contents. In a study of three healthy adult volunteers, a $600 \mathrm{mg}$ oral dose was extensively absorbed ( $\geq 85 \%){ }^{25}$ Absorption is believed to be dissolution rate-limited and takes place in the small bowel. ${ }^{26}$ The maximum plasma concentration (mean) was reached within 6.6 hours after a single $400 \mathrm{mg}$ dose. ${ }^{27}$ In three studies analyzing the influence of food on absorption in healthy adult subjects, taking rufinamide within one hour from mealtimes did not significantly affect plasma concentrations. However, bioavailability is significantly increased with administration after a high-fat meal versus administration after prolonged fasting. Prolonged fasting may decrease plasma levels and decrease seizure protection..$^{26}$ Administration with food is recommended.$^{23}$

Rufinamide is approximately $34 \%$ bound to plasma proteins. ${ }^{26}$ It is extensively metabolized to a carboxylic acid derivative (CGP 47292) and to glucuronide conjugates of CGP 47292. Very small amounts of the parent drug are found in the urine and feces. About $85 \%$ of the drug is eliminated renally. Rufinamide is not believed to be metabolized via the cytochrome P450 system. ${ }^{27,28}$ It displays monoexponential elimination, with a mean half-life of about nine hours in adults. ${ }^{27}$

A population analysis in 117 children (4-11 years) and 99 adolescents (12-17 years) determined that the pharmacokinetics of rufinamide were similar to those seen in adult studies. ${ }^{23}$ In a pharmacokinetic study of 129 adults and children with LGS, a decrease in bioavailability was observed with higher doses in the children. Clearance is also proportional to body surface area; therefore, children 
display higher steady-state concentrations and lower clearance compared with adolescents or adults. ${ }^{29}$

Rufinamide has a low potential for drug-drug interactions due to its lack of protein binding and metabolism independent of the cytochrome P450 system. This lack of significant drug interactions has been demonstrated clinically through a pharmacokinetic analysis using data from five double-blind studies in adults and children. ${ }^{30}$ Rufinamide was coadministered with carbamazepine $(n=903)$, valproic acid $(n=588)$, lamotrigine $(n=200)$, phenytoin $(n=299)$, phenobarbital $(n=149)$, and topiramate $(n=69)$. Rufinamide did not affect the clearance of topiramate or valproate, but increased the clearance of carbamazepine and lamotrigine, and decreased clearance of phenobarbital and phenytoin. However, these interactions were not considered clinically significant. ${ }^{30}$ Another study demonstrated that rufinamide concentrations increased with concomitant valproate by $40 \%$ and $11 \%$ in children and adults, respectively. Therefore, dose reduction may be required with the initiation or withdrawal of concomitant valproate. ${ }^{29}$ Rufinamide also resulted in a small increase in the clearance of the oral contraceptive Ortho-Novum ${ }^{\circledR}$ (ethinyl estradiol and norethindrone); however, the clinical significance of this interaction has not been elucidated. ${ }^{31}$

\section{Safety}

In a randomized, double-blind, placebo-controlled trial of rufinamide in 138 children and adults with LGS, the majority of reported adverse effects were similar between placebo and rufinamide at a dose of $45 \mathrm{mg} / \mathrm{kg}$. There were significant differences in somnolence ( $24.3 \%$ with rufinamide versus $12.5 \%$ with placebo) and vomiting (21.6\% with rufinamide versus $6.3 \%$ with placebo). ${ }^{14}$ Cognitive or psychiatric adverse events occurred in a lower percentage of patients taking rufinamide $(17.6 \%)$ versus placebo $(23.4 \%) .{ }^{14}$ Polytherapy increased the risk of adverse effects. During the extension phase of this trial, a total of $113(91.1 \%)$ patients experienced an adverse effect. The most commonly reported adverse effects were vomiting $(30.6 \%)$, pyrexia $(25.8 \%)$, upper respiratory tract infection (21.8\%), and somnolence (21\%). A total of 82 patients discontinued the medication prematurely, $9.7 \%$ due to adverse effects. ${ }^{32}$ The relationship between serum drug concentrations and adverse effects has also been analyzed in 1398 patients from both controlled and clinical studies. The most common adverse effects reported in controlled, double-blind pediatric studies were dizziness (13\%), fatigue $(17 \%)$, nausea $(9 \%)$, vomiting $(7 \%)$, diplopia $(6 \%)$, and somnolence $(7 \%){ }^{26,33}$ Adverse effects were reported in a slightly higher percentage of adults (versus children), those with increased body weight, and in females. Increasing rufinamide plasma concentrations was also associated with an increase in adverse effects. ${ }^{33}$

A pooled analysis of seven clinical studies examined the incidence of adverse events specifically in the pediatric population (212 rufinamide-treated pediatric patients aged 3-16 years, 197 placebo-treated patients aged 4-17 years, and 391 patients in both double-blind or open-label extensions). ${ }^{34}$ Overall, for all studies, 391 patients received an average dose of $41.67 \mathrm{mg} / \mathrm{kg} /$ day for $12-24$ months. The most commonly reported adverse events were vomiting (26.3\%), headache (22.5\%), and pyrexia (18.7\%). ${ }^{34}$ The most common serious adverse effects that occurred in more than one patient were aggravated seizures $(2.8 \%)$, status epilepticus $(2 \%)$, pneumonia $(2 \%)$, and vomiting $(1.5 \%)$. Discontinuation of treatment occurred in $12.5 \%$ due to adverse effects. Five possible cases of AED hypersensitivity syndrome was discovered retrospectively in children younger than 12 years and within the first four weeks of treatment. In the double-blind trials alone, the median dose of rufinamide was $41.96 \mathrm{mg} / \mathrm{kg} /$ day for an average duration of three months. The most common adverse events reported (rufinamide versus placebo) were somnolence $(17 \%$ versus $8.1 \%)$, vomiting ( $16.5 \%$ versus $7.1 \%)$, and headache (16\% versus $8.1 \%)$. Clinically relevant decreases in weight $(\geq 7 \%)$ were seen only in the rufinamide group $(11 / 188,5.9 \%)$ versus an increased incidence of weight gain observed in the placebo group $(15 / 178,8.4 \%)$. The rates of psychiatric adverse events that occurred between rufinamide and placebo were comparable, at $10.4 \%$ versus $14.2 \%$, respectively. Only one patient exhibited QT prolongation and another exhibited electrocardiographic changes (exact change not specified).

In 18 healthy volunteers treated for 18 days with rufinamide, dose-dependent QT interval decreases were reported. ${ }^{35}$ Rufinamide is therefore contraindicated in patients with a short QT interval due to risk of short QT syndrome (syncope, ventricular arrhythmia, possible sudden death). ${ }^{35}$ Obtaining an electrocardiogram prior to initiating rufinamide would be prudent.

\section{Efficacy in Lennox-Gastaut syndrome}

Several trials have evaluated the effectiveness of rufinamide as an adjunctive treatment in LGS (see Table 1). The efficacy of rufinamide as an adjunctive therapy for LGS was evaluated in a multicenter, randomized, placebo-controlled, parallel-group study in 138 patients aged 4-37 (mean 14) years of age. ${ }^{14}$ This study included a 12 -week, double-blind 
Table I Trials of rufinamide for Lennox-Gastaut syndrome in pediatric patients

\begin{tabular}{|c|c|c|c|}
\hline Study & Population & Design & Results \\
\hline Glauser et $\mathrm{al}^{14}$ & $\begin{array}{l}\text { I38 patients } \\
\text { Age } 4-37 \text { years } \\
\text { Mean age } 14.1 \text { years } \\
\text { Patients diagnosed with LGS, having } \\
\geq 90 \text { seizures in month prior to entry, } \\
\text { and receiving stable treatment with } \\
\text { I-3 concomitant AEDs }\end{array}$ & $\begin{array}{l}\text { I2-week, randomized, double-blind, } \\
\text { placebo-controlled, parallel-group } \\
\text { Subjects randomized to rufinamide } \\
\text { up to } 45 \mathrm{mg} / \mathrm{kg} / \text { day ( } 14 \text { days titration) } \\
\text { or placebo in addition to other AEDs }\end{array}$ & 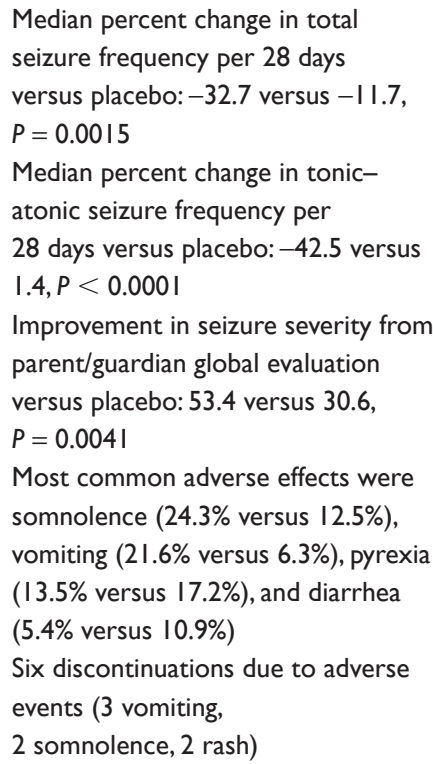 \\
\hline Glauser et $\mathrm{al}^{32}$ & $\begin{array}{l}\text { I } 24 \text { patients from previous study } \\
\text { treated for a median of } 432 \text { days } \\
\text { at } 10-45 \mathrm{mg} / \mathrm{kg} / \text { day } \\
\text { Continued to meet all relevant } \\
\text { inclusion/exclusion criteria } \\
\text { from blinded study }\end{array}$ & $\begin{array}{l}\text { Open-label extension phase } \\
\text { I4-day conversion period }\end{array}$ & $\begin{array}{l}\text { There was a decrease in seizure } \\
\text { frequency observed at all time points } \\
\text { up to } 3 \text { years. Overall } 50 \% \text { response } \\
\text { rate was } 36.9 \% \text {, with a } 44.4 \% \\
\text { reduction in tonic-atonic seizures. } \\
\text { These reductions were consistent } \\
\text { over time. In approximately } 50 \% \\
\text { of patients, the total daily dose of } \\
\text { concomitant AEDs was decreased } \\
\text { over } 30 \text { months of adjunctive } \\
\text { treatment. II } 3 \text { patients ( } 91.1 \% \text { ) } \\
\text { experienced an adverse effect; } \\
\text { I } 2 \text { patients discontinued rufinamide } \\
\text { due to adverse effects. }\end{array}$ \\
\hline Kluger et $\mathrm{a}^{36}$ & $\begin{array}{l}45 \text { children and I } 5 \text { adults } \\
\text { ( } 34 \text { males, average age } 14.5 \text { years) } \\
\text { taking concomitant antiepileptics }\end{array}$ & $\begin{array}{l}\text { I2-week, observational, retrospective } \\
\text { data collection from eight epilepsy } \\
\text { centers in Germany and Austria } \\
\text { Initial dosing/titration at the discretion } \\
\text { of the physician, most started out at } \\
10 \mathrm{mg} / \mathrm{kg} / \text { day }\end{array}$ & $\begin{array}{l}\text { The mean final dose of rufinamide } \\
\text { was } 35.6 \mathrm{mg} / \mathrm{kg} / \text { day. In the analysis } \\
\text { of a subgroup of } 3 \mid \text { patients with } \\
\text { LGS, } 54.8 \%(|7 / 3| \text { ) had a response } \\
\text { rate, defined as a greater than } 50 \% \\
\text { reduction in seizure frequency. Four } \\
\text { patients were seizure-free. } \\
35 \text { ( } 58.3 \%) \text { patients in all subgroups } \\
\text { experienced at least one adverse } \\
\text { event. Mild fatigue, vomiting, and } \\
\text { anorexia were observed in I0\%-I8\% } \\
\text { of patients. No serious adverse } \\
\text { events were reported. A total of } \\
\text { eight patients (I3.3\%) discontinued } \\
\text { rufinamide during the three-month } \\
\text { observation period (four due to } \\
\text { adverse events). }\end{array}$ \\
\hline
\end{tabular}

phase followed by an open-label extension phase. Patients were randomized to placebo or twice-daily oral rufinamide titrated over 7 to 14 days to a daily target dose of $45 \mathrm{mg} / \mathrm{kg}$ in addition to their maintenance regimen. Of note, this trial set a detectable level of significance at 0.025 . The two groups, placebo $(n=64)$ and rufinamide $(n=74)$, were equally distributed demographically except for a slightly higher age and weight in the rufinamide group. Valproic acid, lamotrigine, and topiramate were the most common concomitant medications. Rufinamide serum concentrations 
ranged from 4.95 to $48.15 \mu \mathrm{g} / \mathrm{mL}$. The median reduction from baseline in the frequency of drop attacks per 28 days was significantly greater for rufinamide versus placebo $(-42.5 \%$ versus $+1.4 \%, P<0.0001)$. Absence seizures showed a statistically significant decrease as well. The median reduction from baseline in frequency of all seizures was also significantly greater for study medication versus placebo $(-32.7 \%$ versus $-11.7 \%, P=0.0015)$. These results were associated with a greater proportion of responders (patients achieving $\geq 50 \%$ reduction in seizures per 28 -day period) for rufinamide versus placebo. The responder rate for total seizures was $31.1 \%$ versus $10.9 \%$ and for drop attacks was $42.5 \%$ versus $16.7 \%$ for rufinamide versus placebo, respectively. No patients were determined to be seizure-free during the study. However, $4.1 \%$ of patients demonstrated a $100 \%$ reduction in tonic-atonic seizures. A significant difference related to the parent/guardian global evaluation of the patient's condition at the end of the study was not demonstrated either. There were no significant differences compared with placebo in the incidence of adverse events, apart from somnolence and vomiting, which was higher in the rufinamide group.

Following completion of this study, 123 patients (including 74 males) entered the open-label, treatment-extension phase with a median dose of $1800 \mathrm{mg} /$ day for a median duration of 432 days. ${ }^{32}$ Sixty percent of patients were treated for more than 18 months, $40 \%$ for more than two years, and $12 \%$ for three years or longer. Approximately half of the patients decreased their total daily dose of concomitant AEDs during 30 months of adjunctive therapy with rufinamide. The reduction in median total seizure frequency was maintained, with some improvement noted in patients who continued treatment for up to three years. The responder rate for all seizures was also maintained, with $36.9 \%$ of patients having a $50 \%$ decrease in seizure activity during the open-label phase. In addition, $21.3 \%$ of patients achieved a $\geq 75 \%$ reduction in overall total seizures, with $29.1 \%$ of patients achieving $\mathrm{a} \geq 75 \%$ reduction in tonic-atonic seizures.

The long-term results of rufinamide in an open-label extension trial (trial presented above) were also published by the same research group. ${ }^{36}$ Kluger et al observed patients from 10 to 1149 days, with a median of 432 days. After study termination had occurred (44 months), $33.9 \%$ of patients were still receiving rufinamide, whereas $66.1 \%$ had discontinued due to various reasons, including unsatisfactory therapeutic response $(n=51)$, adverse events $(n=12)$, or other unspecified reasons $(\mathrm{n}=19)$. Notably, patients who had been receiving placebo $(n=59)$ during the double- blind treatment phase went from a $1.5 \%$ decrease in total seizure frequency to a $22 \%$ median reduction in total seizure frequency after two weeks on rufinamide. During the last 12 months of rufinamide treatment, response rates ( $\geq 50 \%$ ) for total seizures and for tonic-atonic seizures were $41 \%$ and $47.9 \%$, respectively. Eight patients (6.8\%) achieved seizure freedom within the last 12 months of rufinamide treatment. More serious adverse events were reported during the extension study (13.7\%) compared with the double-blind study $(2.7 \%)$. Serious adverse events reported and suspected to be treatment-related included rash, constipation, esophagitis, decreased weight, gastritis, anorexia, vomiting, lethargy, and status epilepticus. This trial demonstrated that rufinamide was able to maintain seizure control over the long term. ${ }^{36}$

A 12-week, retrospective, observational study conducted in Europe by Kluger et al included 45 children and 15 adults (mean age 14.5 years) with various refractory epilepsy syndromes. ${ }^{37}$ Thirty-one of the study patients were diagnosed with LGS. Researchers determined response rates by comparing frequency of seizures during the first four-week period of the trial before drug initiation versus seizure frequency with rufinamide during the last four weeks of observation. Seventeen patients with LGS responded to rufinamide (54.8\%), with eight patients exhibiting a 50\%-75\% seizure reduction, five a $75 \%-99 \%$ reduction, and four achieving complete freedom from seizures during the last four weeks of observation. ${ }^{37}$

\section{Other studies}

A three-year cost-efficacy analysis of rufinamide versus lamotrigine and topiramate for children with LGS was conducted in the United Kingdom based on the current published literature. ${ }^{38}$ This study looked at the relationship between costs and quality of life years. Quality of life was based on response rates to each medication, as well as tolerability. Rufinamide had the highest cumulative cost compared with topiramate and lamotrigine. However, the authors concluded that the extra expense for rufinamide was warranted if a patient's quality of life was improved, because LGS can be such a devastating condition.

Currently, there are no direct comparisons of trial data for rufinamide versus other adjunctive therapies for LGS. In addition, a Cochrane review of LGS treatment was unable to compare rufinamide effectively as an adjunctive therapy to other AEDs due to a lack of direct comparison trials, as well as differences in trial designs and population. ${ }^{39}$ This review did suggest, however, that one specific medication has not 
been shown to be more effective than another and, thus, rufinamide, lamotrigine, topiramate, and felbamate should all be considered as an adjunctive treatment for LGS. Patient-specific issues may assist with guiding selection of medication. Rufinamide may be a more efficacious option compared with current alternatives due to the fact that the patients included in the relevant clinical studies may have had more refractory forms of LGS and were already taking multiple AEDs.

\section{Conclusion}

The available literature to date examining rufinamide, a third-generation AED, for the treatment of LGS suggests that it is both a safe and effective adjunctive treatment option for patients who are refractory to therapy with multiple AEDs. The FDA-approved pediatric dosage is up to $45 \mathrm{mg} / \mathrm{kg}$ or $3200 \mathrm{mg} /$ day divided into two doses, which is consistent with effective dosages from the trials. Tablets may be crushed for pediatric administration and the dose should be administered with a meal to increase absorption. ${ }^{23}$ Cost may be a challenge due to the availability of only brand-name dosage forms on the market. However, a pharmacoeconomic analysis ${ }^{38}$ suggests that increased quality of life with rufinamide outweighs its increased cost compared with alternatives.

The most common adverse effects for rufinamide include somnolence, vomiting, dizziness, and fatigue, but these are relatively mild and typically do not warrant drug discontinuation. ${ }^{33}$ Rufinamide is a worthwhile adjunctive treatment for LGS due to its relative lack of clinically significant drug interactions and its acceptable adverse effect profile compared with older anticonvulsants. Additional studies are needed to further assess its short- and long-term efficacy and safety, as well as drug interactions. In addition, a direct comparison between rufinamide and alternative adjunctive treatments is warranted to assess its place in therapy. Rufinamide is a promising adjunctive agent for the treatment of pediatric LGS and may significantly decrease seizure frequency in patients who are refractory to other therapies.

\section{Disclosure}

The authors report no conflicts of interest in this work.

\section{References}

1. Markand ON. Lennox-Gastaut syndrome (childhood epileptic encephalopathy). J Clin Neurophysiol. 2003;20:426-441.

2. Nabbout R, Dulac O. Epileptic encephalopathies: A brief overview. J Clin Neurophysiol. 2003;20:393-397.

3. Guerrini R. Epilepsy in children. Lancet. 2006;367:499-524.
4. Arzimanoglou A, French J, Blume WT, et al. Lennox-Gastaut syndrome: A consensus approach on diagnosis, assessment, management, and trial methodology. Lancet Neurol. 2009;8:82-93.

5. Aicardi J, Levy Gomes A. Clinical and electroencephalographic symptomatology of the 'genuine' Lennox-Gastaut syndrome and its differentiation from other forms of epilepsy of early childhood. Epilepsy Res. 1992;6:185-193.

6. Fitzgerald LF, Stone JL, Hughes JR, et al. The Lennox-Gastaut syndrome: Electroencephalographic characteristics, clinical correlates, and follow-up studies. Clin Encephalogr. 1992;23:180-189.

7. Trevathan E, Murphy CC, Yeargin-Allsopp M. Prevalence and descriptive epidemiology of Lennox-Gastaut Syndrome among Atlanta children. Epilepsia. 1997;38:1283-1288.

8. Genton P, Guerrine R, Dravet C. The Lennox-Gastaut syndrome. In: Meinardi H, editor. Handbook of Clinical Neurology: The Epilepsies, Part II. Amsterdam: Elsevier Science; 2000.

9. Kluger G, Bauer B. Role of rufinamide in the management of LennoxGastaut syndrome (childhood epileptic encephalopathy). Neuropsychiatr Dis Treat. 2007;3:3-11.

10. Begley CE, Famulari M, Annegers JF, et al. The cost of epilepsy in the United States: An estimate from population-based clinical and survey data. Epilepsia. 2000;41:342-351.

11. Roger J, Dravet $\mathrm{C}$, Bureau M. The Lennox-Gastaut syndrome. Cleve Clin J Med. 1989;56 Suppl Pt 2:S172-S180.

12. Panayiotopoulous C. Epileptic encephalopathies infancy and early childhood. A Clinical Guide to Epileptic Syndromes and Their Treatment. 2nd ed. London: Springer; 2007.

13. French JA. The role of new antiepileptic drugs. Am J Manage Care. 2007;7 Suppl:S209-S214.

14. Glauser T, Kluger G, Sachdeo R, et al. Rufinamide for generalized seizures associated with Lennox-Gastaut syndrome. Neurology. 2008; 70:1950-1958.

15. Schmidt D, Bourgeois B. A risk-benefit assessment of therapies for Lennox-Gastaut syndrome. Drug Saf. 2000;22:467-477.

16. No authors listed. Efficacy of felbamate in childhood epileptic encephalopathy (Lennox-Gastaut syndrome). The Felbamate Study Group in Lennox-Gastaut syndrome. N Engl J Med. 1993;328:29-33.

17. Motte J, Trevathan E, Arvidsson JF, et al. Lamotrigine for generalised seizures associated with the Lennox-Gastaut syndrome. Lamictal Lennox-Gastaut Study Group. N Engl J Med. 1997;337:1807-1812.

18. Sachdeo RC, Glauser TA, Ritter F, et al. A double-blind, randomized trial of topiramate in Lennox-Gastaut syndrome. Topiramate YL Study Group. Neurology. 1999;52:1882-1887.

19. Wheless JW, Clarke DF, Carpenter D. Treatment of pediatric epilepsy: Expert opinion. J Child Neurol. 2005;20 Suppl 1:S1-S60.

20. Conry JA, Ng YT, Paolicchi JM, et al. Clobazam in the treatment of Lennox-Gastaut syndrome. Epilepsia. 2009;50:1158-1166.

21. Johannessen Landmark C, Johannessen SI. Pharmacological management of epilepsy: Recent advances and future prospects. Drugs. 2008;68:1925-1939.

22. McClean MJ, Schmutz M, Pozza M, et al. The influence of rufinamide on sodium currents and action potential firing in rodent neurons [Abstr]. Epilepsia. 2005;46 Suppl 7:3.062.

23. Banzel [Package insert]. Woodruff Lake, NJ: Eisai Inc; January 2009.

24. Hutchinson DJ, Liou Y, Best R, et al. Stability of extemporaneously prepared rufinamide oral suspensions. Ann Pharmacother. 2010;44:462-465.

25. Waldmeier F, Gschwind H-P, Rouan M-C, et al. Metabolism of the new anticonvulsive drug rufinamide 9CGP 33101 in healthy male volunteers [Abstr]. Epilepsia. 1996;37 Suppl 5:167(6.60).

26. Perucca E, Cloyd J, Critchley D, et al. Rufinamide: Clinical pharmacokinetics and concentration-response relationships in patients with epilepsy. Epilepsia. 2008;49:1123-1141.

27. Cheung WK, Kianifard F, Wong A, et al. Intra- and inter-subject variabilities of CGP 33101 after replicate single oral doses of two 200mg tablets and 400-mg suspension. Pharm Res. 1995;12:1878-1882. 
28. Bialer M, Johannessen SI, Kupferberg HJ, et al. Progress report on new antiepileptic drugs: A summary of the Fifth Eilat Conference (EILAT V). Epilepsy Res. 2001;43:11-58.

29. Critchley D, Fuseau E, Perdomo C, et al. Pharmacokinetic and pharmacodynamic parameters of adjunctive rufinamide in patients with Lennox-Gastaut syndrome [Abstr]. Epilepsia. 2005;46 Suppl 7:2.351.

30. Fuseau E, Critchley D, Perdomo C, et al. Population pharmacokinetic drug-drug interaction analyses of rufinamide studies in patients with epilepsy [Abstr]. Epilepsia. 2005;46 Suppl 8:2.356.

31. Svendsen KD, Choi L, Chen BL, et al. Single center, open-label, multiple-dose pharmacokinetic trial investigating the effect of rufinamide administration on Ortho-Novum 1/35 in healthy women [Abstr]. Epilepsia. 1998;39 Suppl 6:59.2.111.

32. Glauser T, Kluger G, Sachdeo R, et al. Open-label extension study of the efficacy and safety of rufinamide adjunctive therapy in patients with Lennox-Gastaut syndrome [Abstr 1356]. Epilepsia. 2005; 46 Suppl 6:408.

33. Krauss GL, Perdomo C, Arroyo S. Short-term and long-term safety of rufinamide in patients with epilepsy [Abstr]. Epilepsia. 2005; 46 Suppl 7:3.263.
34. Wheless JW, Conry J, Krauss G, et al. Safety and tolerability of rufinamide in children with epilepsy: A pooled analysis of seven clinical studies. J Child Neurol. 2009;24:1520-1525.

35. Bjerregaard P, Gussak I. Short QT syndrome. Ann Noninvasive Electrocardiol. 2005;10:436-440.

36. Kluger G, Glauser T, Krauss G, et al. Adjunctive rufinamide in Lennox-Gastaut syndrome: A long-term, open-label extension study. Acta Neurol Scand. Mar 1, 2010. [Epub ahead of print].

37. Kluger G, Kurlemann G, Haberlandt E, et al. Effectiveness and tolerability of rufinamide in children and adults with refractory epilepsy: First European experience. Epilepsy Behav. 2009;14:491-495.

38. Verdian L, Yi Y. Cost-utility analysis of rufinamide versus topiramate and lamotrigine for the treatment of children with Lennox-Gastaut syndrome in the United Kingdom. Seizure. 2010;19:1-11.

39. Hancock E, Cross H. Treatment of Lennox-Gastaut syndrome. Cochrane Database Syst Rev. 2003:CD003277.
Neuropsychiatric Disease and Treatment

\section{Publish your work in this journal}

Neuropsychiatric Disease and Treatment is an international, peerreviewed journal of clinical therapeutics and pharmacology focusing on concise rapid reporting of clinical or pre-clinical studies on a range of neuropsychiatric and neurological disorders. This journal is indexed on PubMed Central, the 'PsycINFO' database and CAS, and is the official

\section{Dovepress}

journal of The International Neuropsychiatric Association (INA). The manuscript management system is completely online and includes a very quick and fair peer-review system, which is all easy to use. Visit http://www.dovepress.com/testimonials.php to read real quotes from published authors. 